\title{
An Unusual Case of Maxillary First Premolar with Three Root Canals having Two Canals in Buccal Root and One in Palatal
}

\author{
${ }^{1}$ Yogesh Sahu, ${ }^{2}$ Aditi Jain
}

\begin{abstract}
For achieving high levels of success in endodontic therapy a thorough knowledge of internal dental anatomy is fundamental. Lack of understanding of anatomic variations has been pointed as one of the main causes of endodontic therapy failure. Clinicians need to be aware of the unusual numbers of roots and root canal, and it is a challenge to treat teeth with extra roots and/or canals. This case report presents a rare case of successful nonsurgical endodontic management of maxillay first premolar with three roots having two canals in buccal root and one in palatal root canal.
\end{abstract}

Keywords: Anatomy, Missed canal, Premolar, Two buccal canals.

How to cite this article: Sahu Y, Jain A. An Unusual Case of Maxillary First Premolar with Three Root Canals having Two Canals in Buccal Root and One in Palatal. $\mathrm{J}$ Health Sci Res 2018;9(1):20-22.

Source of support: Nil

Conflict of interest: None

\section{INTRODUCTION}

Vertucci ${ }^{1}$ in 1979 studied first the anatomy of maxillary first premolars and reported $5 \%$ of 400 maxillary first premolars have three canals: $0.5 \%$ of them with three canals in a single root, $0.5 \%$ have three canals in two roots, and $4 \%$ have three canals in three roots. A thorough understanding of the normal as well as anatomical variations is required for the successful and predictable endodontic treatment outcome. Carns and Skidmore ${ }^{2}$ reported three separate canals in $6 \%$ of the maxillary first premolar teeth. Failure to recognize unusual numbers of roots and their anatomy can result in the failure of endodontic therapy. Hence, it is imperative that the clinician should be astute enough to the commonest possible variations. Hoen and

\footnotetext{
${ }^{1}$ Reader, ${ }^{2}$ Senior Lecturer

${ }^{1,2}$ Department of Conservative Dentistry and Endodontics Maitri College of Dentistry and Research Center, Rajnandgaon Chhattisgarh, India

Corresponding Author: Aditi Jain, Senior Lecturer, Department of Conservative Dentistry and Endodontics, Maitri College of Dentistry and Research Center, Rajnandgaon, Chhattisgarh India, Phone: +919425516882, e-mail: aditijain300789@gmail. com
}

Pink $^{3}$ revealed $42 \%$ incidence of missed roots or canals in their analysis on teeth requiring retreatment. The aim of this article is to report the successful endodontic treatment of a maxillary first premolar with two buccal canals and one palatal canal.

\section{CASE REPORT}

A 32-year-old female patient reported to the Department of Conservative Dentistry, Maitri Dental College and Research Institute, Rajnandgaon, India with the chief complaint of spontaneous toothache in her right upper back region of the jaw since 5 days. The patient's medical history was unremarkable. Past dental history revealed previous endodontic treatment performed in relation to maxillary first premolar 1 week back. Presently, patient was having continuous pain and sensitivity to cold. The premolar was tender on percussion, was not mobile, and periodontal probing around the tooth was within physiological limits. Radiographic examination revealed two canals: Obturated one is buccal and second is palatal (Fig. 1). Considering some extra canal that might be present, retreatment was planned and suggested to the patient. Local anesthesia was administered with $2 \%$ lidocaine and 1:80,000 epinephrine (DarouPakhsh, Tehran, Islamic Republic of Iran) and an OptraDam was placed. Old restoration was removed. On proper cleaning of pulp chamber, obturating materials were seen on buccal and

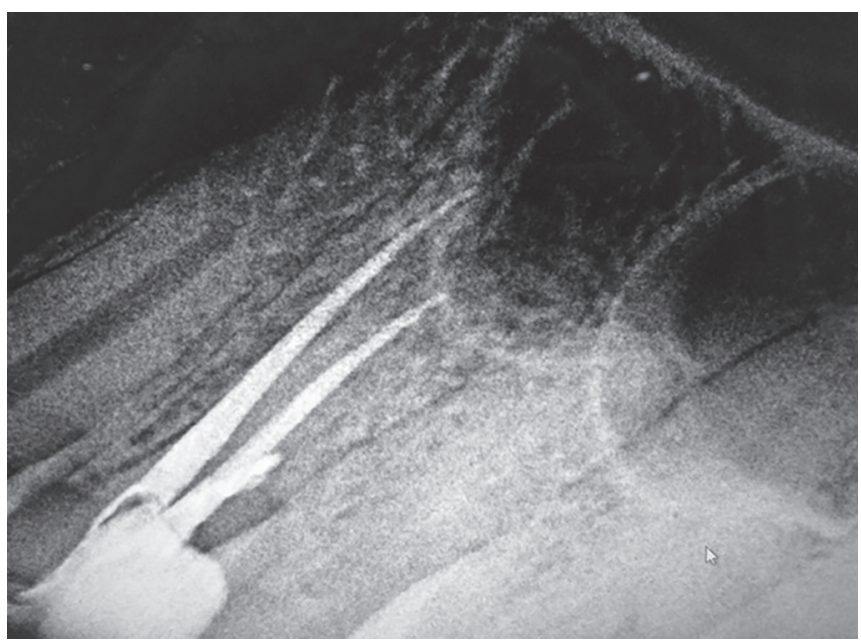

Fig. 1: Radiograph revealed two canals obturated: one buccal and one palatal 


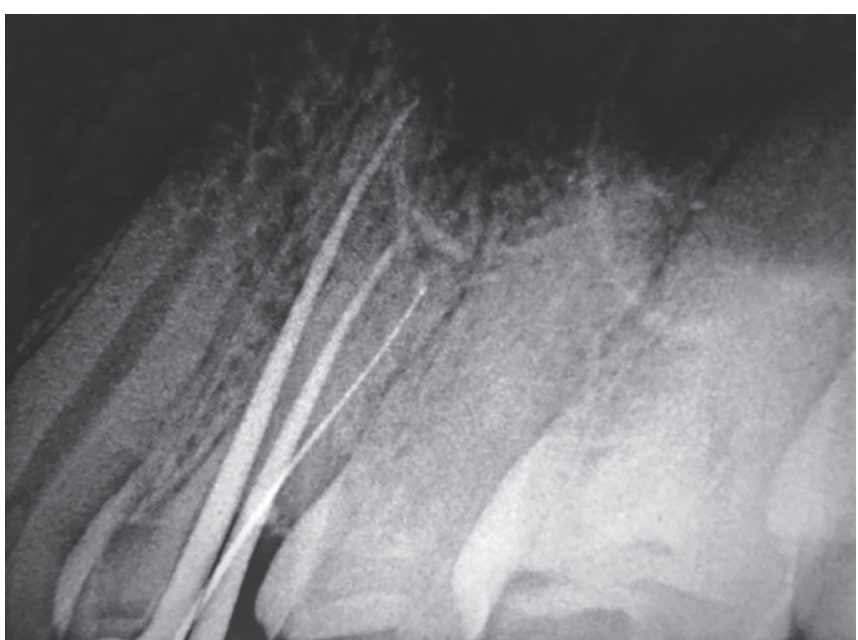

Fig. 2: Working length estimation of extra canal located buccally

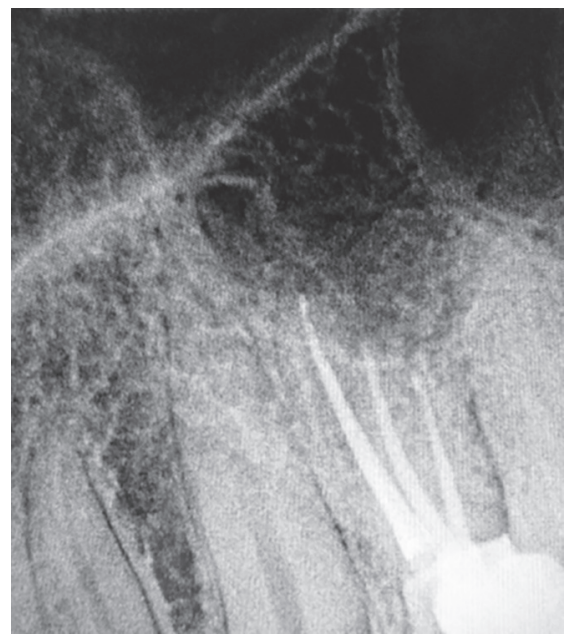

Fig. 4: Three canals obturated radiograph

palatal aspects. In view of possibility of extra canals, the access opening was modified and troughing performed buccolingually and it was made wider mesiodistally than normal on the buccal aspect, making the access opening T-shaped. Dentinal map on the floor of the pulp chamber was traced to locate one separate opening in buccal canals. After negotiation and verification, working length with electronic apex locator (Root ZX, Morita, Japan) and later confirmation with intraoral periapical X-ray revealed there was one extra canal present in buccal roots (Fig. 2). The old obturating materials were removed using rotary nickel-titanium (NiTi) ProTaper retreatment system (Dentsply Maillefer). The extra canal was cleaned and shaped using $\mathrm{k}$ files till size 15. Canal was instrumented sequentially with protaper rotary NiTi instruments (Dentsply Maillefer) using crown down technique. Irrigation was performed using $5.25 \%$ sodium hypochlorite, normal saline, and $17 \%$ ethylenediaminetetraacetic acid (EDTA). Calcium hydroxide paste was given as an intracanal medicament, and cavity was sealed with interim restorative material (IRM). Calcium hydroxide

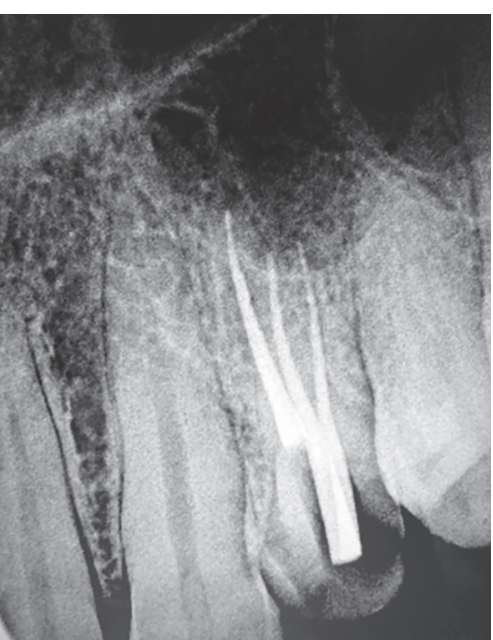

Fig. 3: Master cone selection radiograph

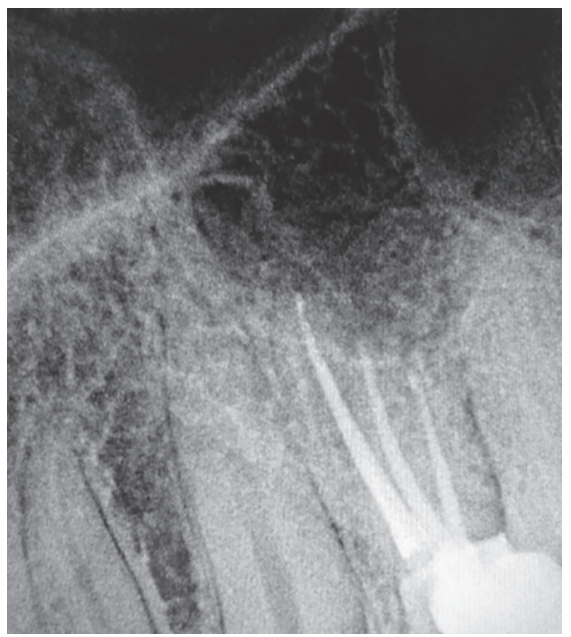

Fig. 5: Six months follow-up radiograph

was used as interappointment dressings in recall visits. The canal was finally rinsed with normal saline and $17 \%$ EDTA. The canals were dried with respective size sterile absorbent paper points (Dentsply Maillefer) and obturated with AH26 resin sealer (Dentsply Maillefer, Konstanz, Germany) and respective gutta-percha cones (Dentsply Maillefer) with warm vertical condensation technique (Fig. 3). Temporary restoration was done with IRM, postobturation radiograph taken to confirm quality of obturation, and the tooth was restored using posterior resin composite (P60; 3M Dental Products, St. Paul, Minnesota, USA) (Fig. 4). The patient was asymptomatic during the follow-up period of 6 months (Fig. 5).

\section{DISCUSSION}

According to reported dental literature, root canal morphology of teeth varies greatly and one of the major challenges in endodontic therapy is to treat teeth with variable anatomic configurations. The careful examination of preoperative radiographs taken from different horizontal angles is essential for the complete assessment 
of root canal morphology and anatomy. In case of a doubt regarding possible variations in dental anatomy, two diagnostic X-ray images are recommended. ${ }^{1-4}$ If suddenly the X-ray image of a wide and well-shaped root canal narrows or disappears, it is assumed that there is a special root anatomy and probably a split of the root canal. ${ }^{4-6}$ The careful inspection of the shape of the pulp chamber might be a signal for a greater number of root canals. 3,4,7,8 The buccal pulp horn is larger than the palatal pulp horn. The mean distance is 3.13 and 5.08 $\mathrm{mm}$ respectively, between the most cervical region of the pulp chamber roof and the canal bifurcation and trifurcation. Establishing the presence of three root canals in the presented endodontic treatments of maxillary first premolars is a prerequisite for successful endodontic practice. The study of the anatomy of the maxillary first premolar reveals significant anatomical variations. The establishment of three canals in maxillary first premolars ranges from 1.2 to $6 \%$ according to various authors. ${ }^{2,7,9}$ Definitely much rarely three canals of maxillary first premolar can be observed in Asian population. An interesting anatomical feature has been reported by Sieraski et al. ${ }^{5}$ When the mesiodistal width of the middle part of the root in the X-ray is equal to or greater than the width of the tooth's crown, it is possible that we have three roots in the maxillary first premolar.

\section{CONCLUSION}

Knowledge of dental anatomy is fundamental for good endodontic practice. Clinicians must have adequate knowledge about root canal morphology and its variations. Although the frequency of maxillary premolars with three root canals is rare, each case should be investigated carefully both clinically and radiographically, to detect the anatomical anatomy and its variations to get successful endodontics.

\section{REFERENCES}

1. Vertucci FJ. Root canal anatomy of the human permanent teeth. Oral Surg Oral Med Oral Pathol 1984 Nov;58(5):589-599.

2. Carns EJ, Skidmore AE. Configuration and deviation of root canals of maxillary first premolars. Oral Surg Oral Med Oral Pathol 1973 Dec;36(6):880-886.

3. Hoen MM, Pink FE. Contemporary endodontic retreatments: An analysis based on clinical treatment findings. J Endod 2002 Dec;28(12):834-836.

4. Kirilova J, Chaucheva B, Razsipyiska İG. The case with three canals of first maxillary premolar. Probl Dent Med 2009;35(2) 80-82.

5. Sieraski SM, Taylor GN, Kohn RA. Identification and endodontic management of three-canalled maxillary premolar. J Endod 1989 Jan;15(1):29-32.

6. Vier-Pelisser FV, Dummer PM, Bryant S, Marca C, Só MV, Figueiredo JA. The anatomy of the root canal system of threerooted maxillary premolars analysed using high-resolution computed tomogaphy. Int Endod J 2010 Dec;43(12):1122-1131.

7. Victorio FR, Men-Martins M. Maxillary first premolar with three roots. Case report. Dent Press Endod 2013 Jan-Apr;3(1): 73-77.

8. Arizu HD, Alacam T. Diagnosis and treatment of three-rooted maxillary premolars. Eur J Dent 2009 Jan;3(1):62-66.

9. Nica L, Ianes C, Florita Z. Root canal treatment of a threerooted maxillary first premolar - a case report. Endod Pract Today 2011;5(1):63-66. 